\title{
The Use of Giardia immunogenic Protein Fraction to Distinguish Assemblages in Humans and Animals
}

\author{
Reem M. Ramadan ${ }^{1}$, Marwa M. Khalifa ${ }^{1}$, Nancy O. Kamel ${ }^{2}$, Azza M. Abdel-Wahab ${ }^{1}$, and Mohamed M. El-Bahy ${ }^{{ }^{*}}$ \\ ${ }^{I}$ Department of Parasitology, Faculty of Veterinary Medicine, Cairo University, P.O. 12211 Giza, Egypt \\ ${ }^{2}$ Faculty of Medicine, October 6 University, Giza, Egypt \\ *Corresponding author's Email: putut.riyadi@live.undip.ac.id; (DORCiD: 0000-0003-2940-4108
}

\begin{abstract}
Buffalo calves have a high adverse effect on public health, specifically zoonotic Giardiasis in Egypt. The current study was carried out to investigate the use of enzyme-linked immunoelectrotransfer blot technique (EITB) as a preliminary step for the diagnosis of giardiasis before genotyping. For this purpose, fecal and blood samples were collected from diarrheic calves and workers in closed and non-closed beef buffalo farm. Zoonotic Giardia assemblage A was isolated from both diarrheic children and their close contact calves while the calves were infected by animal genotype assemblage $\mathrm{E}$ under low contact conditions. This was identified after the amplification and sequencing of a 292 bp fragment of 16S-rRNA ribosomal unit from 20 children and 28 calves Giardia isolates using nested PCR. Fractionation of different isolated Giardia assemblage and identification of specific fraction versus antiGiardia-IgG antibodies in infected humans or animals using EITB revealed that $\alpha-1$ giardin antigen with molecular weight ranged 29-34KDa. This specific immunogenic assemblage was fraction-related where it reacted specifically versus antibodies in sera of humans or animals infected by this assemblage and did not cross-react with giardin of other assemblage or with sera of non-infected cases. The results of the current study highlighted the use of EITB as a preliminary investigation before genotyping in the identification of zoonotic giardiasis.
\end{abstract}

Keywords: Buffalo calves, Genotype, Giardia, Human, Immunoblot, Nested PCR

\section{INTRODUCTION}

Giardia duodenalis (Syn. G. intestinalis, G. labmlia) is a worldwide distributed zoonotic protozoan parasite infecting humans as well as domestic and wild animals with high levels of genetic diversity. The parasite is re-emerging as one of the most frequent causes of diarrhea in humans which infects about 200 million people worldwide causing a serious public health concern as each individual eliminates up to $10^{8}$ to $10^{10}$ cysts per day. The parasite is extensively distributed in children, especially those living in rural communities in developing countries. The high prevalence of this disease among humans in some localities is associated with its high prevalence in some of the surrounding animals (Coffey et al., 2020).

Giardia duodenalis is considered to be a complex species and its members are being morphologically indistinguishable using traditional diagnostic techniques. Genotypic analysis based on Polymerase chain reaction technology has made an enormous contribution to understanding the genetic structure of different Giardia species, molecular epidemiology of infection, and zoonotic transmission (Mahmoudi et al., 2020). Based on molecular genetic analyses, G. duodenalis are grouped into eight recognized genotypic clusters or assemblages (A-H). Assemblages A and $\mathrm{B}$ are zoonotic occurring in humans and many other hosts, assemblages $\mathrm{C}$ and $\mathrm{D}$ have been diagnosed only in dogs, assemblage $\mathrm{E}$ has been reported only in hoofed animals, assemblages $\mathrm{F}$ and $\mathrm{G}$ have been observed only in cats and rodents respectively, and assemblage $\mathrm{H}$ in pinnipeds. The factors affecting host specificity are partially understood where it involves both the host and the parasite (Cacciò et al., 2018). Human isolated assemblages (A and B) have been further sub-grouped using conserved loci into AI, AII, BIII, and BIV (Ramírez et al. 2015). Assemblage AI is the most frequent sub-assemblage that is highly associated with animals while that of AII is limited to humans (Puebla et al., 2017).

Other than the traditional parasitological ways used for diagnosis of different stages of Giardia in feces, several enzyme immunoassays are also applicable to use. However, most of these methods are qualitative and unable to distinguish different Giardia genotypes (Hooshyar et al., 2019). Characterization of specific protein fraction from the parasite antigens by enzyme-linked immunoelectrotransfer blot technique (EITB) may benefit from an accurate specific way for diagnosis. Several immunogenic protein fractions of Giardia have been described, such as cyst wall proteins (CWPs), variable surface proteins (VSPs), giardins, arginine deaminase, and tubulins. The CWPs and proteins $\alpha-1$ giardin provide marked protection against G. lamblia infection (Quintero et al., 2013). Special protein fractions were identified in Giardia cysts as specific diagnostic antigens for the detection of the A.G. Abs in sera of infected cases, such as the fractions corresponding to molecular weight (MW) of 26, 28, 38, 42, $46 \mathrm{kDa}$ (Campbell and Faubert, 1994), that 
of 29, 75, 88, $102 \mathrm{kDa}$ (Erlandsen et al., 1990), and that of MW of 38, 36, 34, 33, and $29 \mathrm{kDa}$ (Trout et al., 2004). In a study conducted by Quintero et al. (2013), $\alpha-1$ giardin was identified as a group of protein fractions at MW of 29-33 kDa for G. lamblia of humans and these specific fractions could be used for the diagnosis of anti-Giardia-IgG antibodies (A.G. Abs) in sera of infected cases.

The present study was conducted due to the presence of an emerging diarrhea problem in a closed buffalo-calves farm. Different stages of Giardia were diagnosed in diarrheic fecal samples collected from these calves, the children of the farmworkers, and some villagers with a history of diarrhea living outside this farm. Most people in this village were farmers and lived in intimate contact with these animals.

The current study was intended to investigate the distribution and persistence of giardiasis in human-animal contact in a semi-closed community. Moreover, the study was targeted toward the investigation of the genotyping identification of the obtained Giardia isolates. Finally, it aimed to investigate the presence of specific immunogenic antigenic fractions related to the isolated Giardia assemblage which can facilitate assemblage identification using EITB as a preliminary method of identification before genotyping.

\section{MATERIALS AND METHODS}

\section{Ethical approval}

The employed protocol was approved by the Faculty of Medicine Cairo University Ethics Committee, Giza, Egypt, after the agreement of local health authorities for all participants. Procedures used for handling the animals, collection of samples, and the use of the patients' samples during this study were assessed and approved by the institutional review board of the Institutional Animal Care and Use Ethical Committee (Vet. CU20022020132) of Cairo University, Egypt.

\section{Sample collection and examination}

Identified fecal and blood samples were collected from diarrheic calves and workers in two levels of human-animal contact. The primary one consisted of 40 calves (one week to 6 months) and 20 children (one month-5 years old) live in intimate contact with closed beef buffalo farm (defined as closed farm samples). The second group composed of 78 calves and 40 children present in 4 non-closed breeding pins; each contained an occasional number of animals moved freely for grazing along with the village with their owners (this group defined as open farm samples). The study was performed from October to December 2019 in Abo-Rawash village, south of Giza Governorate, Egypt. Rectal or fresh deposited fecal samples were collected in identified plastic containers, preserved in ice, and transferred to the Department of Parasitology, Faculty of Veterinary Medicine, Cairo University for examination. Giardia cysts or trophozoites were detected using the modified Telemann method according to Fugassa (2014). Serum samples were separated from the collected blood after clotting by centrifugation and stored at $-20{ }^{\circ} \mathrm{C}$ until use.

\section{Cyst purification and antigen extraction}

According to Ehsan et al. (2015), a sufficient amount of each fecal sample was filtered through two layers of surgical gauze and adjusted to yield a volume of $7 \mathrm{ml}$ of filtrate. In the next step, the filtrate was layered over $5 \mathrm{ml}$ of $1 \mathrm{M}$ sucrose (1.13 specific gravity) and centrifuged at $800 \mathrm{xg}$ for $5 \mathrm{~min}$ for the cyst concentration at the sucrose/water interface. The interface layer and the upper layer of the liquid were transferred by a suitable pipette to another clean tube, then re-centrifuged again as mentioned earlier. The supernatant was decanted, the sedimented pellet was re-suspended in $1 \mathrm{ml}$ PBS and stored at $4{ }^{\circ} \mathrm{C}$ as concentrated Giardia cysts.

For the preparation of the required cyst antigens, the collected purified cysts were disrupted according to the method proposed by David et al. (2011). The cysts were subjected to 6 cycles of freezing and thawing (from $-70{ }^{\circ} \mathrm{C}$ to $+70{ }^{\circ} \mathrm{C}, 30$ minutes in each cycle), then they were selected for use as either DNA isolation or antigen fractionation. For the former, the mixture was incubated with proteinase $\mathrm{K}(1 \mathrm{mg} / \mathrm{ml})$ and lysis buffer $(\mathrm{NaCl} 0.15 \mathrm{M}$, EDTA 0.1 M, SDS $0.5 \%$, pH 7.8, at $37{ }^{\circ} \mathrm{C}$ for 24 hours) where this suspension was stored at $-20{ }^{\circ} \mathrm{C}$ until use. For the latter, Giardia cyst antigen was extracted according to Quintero et al. (2013), the disrupted cyst mixture was centrifuged (15000 rpm for 1 hour at $4{ }^{\circ} \mathrm{C}$ ). Afterward, the supernatant was aspirated and after the estimation of its protein content, it was used as crude Giardia cyst soluble antigen and stored at $-70{ }^{\circ} \mathrm{C}$ until use.

\section{Fractionation of Giardia cyst antigen}

Giardia cyst antigen representing human and animal's localities and age groups were fractionated using SDSPAGE (Laemmli, 1970). Using PROTEAN II Xi cell and Bio-Rad, the antigens were resolved in $12 \%$ polyacrylamide gel slabs under reducing conditions. Prestained MW standard was employed (Bio-Rad Cat. \#.161-0318). The comb was adjusted as one small well for the MW standard and a large one for the samples. 


\section{Determination of specific protein fractions}

The fractionated proteins were transferred into $(0.2 \mu \mathrm{m}$ pore size $)$ nitrocellulose sheet and determined using EITB according to a study conducted by Towbin et al. (1979). Longitudinal NC strips (0.3 cm wide) containing the fractionated antigens were cut out, treated with known infected human and animal serum (1:100) of known cyst/gram feces in_comparison with negative control sera. Anti-human and anti-bovine IgG peroxidase were conjugated (Sigma Immunochemicals, 1:2000 dilution). The color was developed in a 4-chloro-1-naphthol substrate. Specific protein fractions reacted positively versus its Giardia infected sera and at the same time did not react versus negative serum samples.

\section{Purification of Giardia cyst and DNA extraction}

An amount of $100 \mu \mathrm{l}$ of cyst suspension from Giardia positive calves' samples was selected for DNA extraction using a genomic DNA purification kit (Gentra system Instruction, Minnesota USA) according to the instructions manual designed by Hawash (2014). Samples were destructed by exposure to six freezing and thawing cycles in liquid nitrogen. After this, $100 \mu \mathrm{l}$ of tissue lysogenic buffer was added, samples were incubated at $80^{\circ} \mathrm{C}$ for 5 minutes, then centrifuged at $10000 x g$ for 15 seconds. The supernatant was transferred to another clean tube then a $15 \mu 1$ RNase solution was added to the mixture and it was mixed for 25 times then incubated at $37{ }^{\circ} \mathrm{C}$ for $15-60$ minutes. After cooling at room temperature, one $\mathrm{ml}$ protein precipitation solution was added to the cell lysate, vortices for 20 seconds then centrifuged at 2000x g for $10 \mathrm{~min}$. The supernatant containing the DNA was transferred to another tube containing $3 \mathrm{ml}$ of absolute Isopropanol, mixed well, and centrifuged at 2000x g for 3 minutes. After the removal of the supernatant, $200 \mu \mathrm{DNA}$ hydration solutions were added and left for 1 hour at $65^{\circ} \mathrm{C}$. The spectrophotometer quantization of the DNA was performed according to Saiki et al. (1988) and stored at $-20^{\circ} \mathrm{C}$ for PCR amplification. Representative samples from each Giardia positive calves were selected for DNA extraction and genotyping.

\section{Amplification and sequencing}

The PCR protocol described by Almeida et al. (2015) was used for the amplification of 16S-rRNA ribosomal unit fragment. Nested PCR protocol was applied by using initial primers Gia2029 (5'-AAGTGTGGTGCAGACGGACTC-3') and Gia2150c (5'-CTGCTGCCGTCCTTGGATGT-3') amplifying a 497 bp product and secondary primers RH11 (5'CATCCGGTCGATCCTGCC-3') and RH4 (5'-AGTCGAACCCTGATTCTCCGCCAGG-3') generating a 292 bp fragment.

The PCR reactions consisted of 1-5 $\mu \mathrm{l} \mathrm{DNA}, 2.0 \mathrm{mM} \mathrm{MgCl} 2,200 \mu \mathrm{M}$ each dNTP, 5\% DMSO, 12.5 pmol for each of the forward and reverse primer, 0.5 Units of Taq polymerase (Qiagen, Germany), 0.5 Units of TAQ Extender ${ }^{\mathrm{TM}}$ (Stratagene, USA) $1 \times$ PCR buffer (Qiagen). The polymerization program includes 35 PCR cycles $\left(96{ }^{\circ} \mathrm{C}\right.$ for $45 \mathrm{~s}, 55^{\circ} \mathrm{C}$ for $30 \mathrm{~s}, 72{ }^{\circ} \mathrm{C}$ for $45 \mathrm{~s}$ ) with an initial hot start $\left(96^{\circ} \mathrm{C}\right.$ for $\left.4 \mathrm{~min}\right)$ and its final extension as $\left(72{ }^{\circ} \mathrm{C}\right.$ for $4 \mathrm{~min}$ ) was carried out using Perkin-Elmer Gene/ Amp PCR System 2400 (Wouters \& Wouters EMS Services, USA). The conditions of the secondary PCR cycle were identical to the primary one except it occurs with increasing the annealing temperature to 59 ${ }^{\circ} \mathrm{C}$. The purification of the obtained PCR products occurred by Qiagen PCR Agarose Purification Kit (Qiagen, 28004) and sequenced in both directions using $\mathrm{ABI}$ Prism $^{\mathrm{TM}}$ Rhodamine Terminator Cycle Sequencing Kit (Applied BioSystems, USA) guided by the manufacturer's instructions, with the reduction of the annealing temperature to $59^{\circ} \mathrm{C}$, halved the reaction volumes to $10 \mu \mathrm{l}$, and increasing the cycles to 35 . The sequences of the samples were analyzed using SeqEdv1.0.3. (Applied BioSystems, USA). Finally, the alignment of sequence information obtained from different calves' isolates was compared with those obtained from GenBank accession numbers AF113902 and AF199446u using Clustal W (Thompson et al., 1994).

\section{RESULTS}

\section{Significance of calves' giardiasis on public health}

Microscopic examination of the diarrheic fecal samples collected from 40 buffalo calves and 20 intimately contact children in the closed farm revealed different stages of infection induced by Giardia in all young calves (less than 2 months old). However, the infection was $40 \%$ in older calves (2-6-month-old) with the total percentage of infection reached $62.5 \%$. The infection in the contact children inside this farm was estimated at $75 \%$ with a high prevalence in children aged 2-5 years. Investigation of diarrheic calves and their owners in four sporadic other pins revealed that $48.71 \%$ of the investigated calves were infected and the highest rate was related to young calves aged less than 2 months $(53.33 \%)$. The infection in children of the owners of these animals was determined at $60 \%$ with a higher percentage in children of 2-6 months old (Table 1). 


\section{Genotypes of diagnosed Giardia isolates from children \& calves}

To genotype the obtained Giardia isolates, a total number of 12 calves isolates and 8 human isolates from the 25 infected calves and the 15 human isolates were selected from the infected cases in the closed farm. Moreover, four calves' Giardia isolates and three human isolates from each of the other four investigated open pens in the infected groups were selected for genotyping. The sequencing of the samples was applied at the 16S-rRNA locus. All of the sequenced human isolates in the closed and open farm (8 and 12 samples) as well as the 12 isolates of calves derived from infected animals in the closed farm revealed the same genetic sequence with $100 \%$ identity as the ones recorded in the gene-bank for Giardia assemblage A genotype (AF199446, Figure 1). At the same time, the other calve isolates (i.e., 16 samples) isolated from infected calves in the open pens had sequences computable to previously described isolates for genotype (Assemblage) A sequence except that they had a variation in a single nucleotide, A-G transition at the site of nucleotide position 92. These changes were compatible with the proposed "Hoofed livestock" genotype (AF113902, E) that recorded in the gen-bank for cattle Giardia assemblage E. More characterization for the obtained Giardia assemblage $\mathrm{A}$ in other separate work proved that the isolated human assemblage A recorded in this study was identified as assemblage A1.

\section{Giardia specific fraction from human and animal}

Treatment of fractionated Giardia cysts assemblage A isolated from infected children versus sera of all assembling A infected children (sample in Lane1), sera of calves live in the closed farm (sample in Lane 3) and sera of calves infected by livestock assemblage E (sample in Lane 2) revealed that the fractions of 55, 46, and 25 KDa reacted as specific fractions, compared to all of the above different infected sera. The fraction at MW of 38 KDa in this fractionated human isolate (assembling A) reacted specifically versus infected calves' sera and did not react versus infected human sera. Broad polypeptides band corresponding to MW ranged 29-34 KDa reacted specifically versus sera of children and calves infected by assemblage A only (Calves infected in the closed farm). Meanwhile, it did not react versus calves' sera collected from the other open-farm and diagnosed as infected by assemblage E (Table 2 and plate 1).

Treatment of fractionated calves' Giardia isolates (assemblage E) versus sera of infected calves from open pins (sample in Lane 6 infected by the same assemblage), or those from calves (Lane 7) or children (sample in Lane 8) in the closed farm (infected by assemblage A) revealed specific reaction versus polypeptides at MW of $55 \mathrm{KDa}, 46 \mathrm{kDa}, 25$ $\mathrm{KDa}$, and $18 \mathrm{KDa}$. Moreover, the fraction of $38 \mathrm{KDa}$ was reacted in these calves isolate versus infected children serum. These calves strain reacted by broadband $(45-50 \mathrm{KDa})$ in the region corresponding to $46 \mathrm{KDa}$ versus infected children sera. The most interesting reaction was recorded versus the fraction of 29-34 KDa, this group of bands was reacted specifically in the calves with assemblage E versus calves with infected sera by this assemblage (Lane 6). At the same time, they did not react versus sera of children or calves infected by assemblage A. Moreover, there was a narrow band at MW of $29 \mathrm{KDa}$ (Lane 7) versus calves from the closed pin. None of the above-mentioned bands reacted positively versus negative human or calves' sera in both types of antigens (Lane 4, 5, 9, and 10) (Plate 1). The fraction corresponding to MW standard at 100, 70, 15, and $12 \mathrm{KDa}$ in fractionated isolates of children and those at MW of 100 $\mathrm{KDa}$ and $70 \mathrm{KDa}$ in fractionated isolates of calves were identified as non-specific fractions as they reacted versus infected and non-infected serum samples (Plate 1).

\begin{tabular}{|c|c|c|c|}
\hline Sample & $\begin{array}{l}\text { Base pair } \\
\text { region }\end{array}$ & Sequence & $\begin{array}{c}\text { Base pair } \\
\text { region }\end{array}$ \\
\hline Assemblage A & 1 & CATCCGGTGGATCCTGCCGGAGCGCGACGCTCTCCCCAACGAC-GAAGCC & 49 \\
\hline Livestock & 1 & CATCCGGTGGATCCTGCCGGAGCGCGACGCTCTCCCCAACGAC-GAAGCC & 49 \\
\hline Assemblage A & 50 & ATGCATGGCCGCTCACCCGGGACGCCGCGACGGCTCAGGACAACCGTTG & 99 \\
\hline Livestock & 50 & ATGCATGGCCGCTCACCCGGGACGCCGCGACGGCTCAGGAC馬CGTTG & 99 \\
\hline Assemblage A & 100 & CACCGCCCGCGGCGGTCCCTGCTAGCCGGACACGGCTGGCAACGCGGCGC & 149 \\
\hline Livestock & 100 & CACCGCCCGCGGCGGTCCCTGCTAGCCGGACACGGCTGGCAACGCGGCGC & 149 \\
\hline Assemblage A & 150 & CAAGACGTGCCCGCAAGGGCGGGCGCGCGCGGGCGAGCAGCGTGACGCAG & 199 \\
\hline Livestock & 150 & CAAGACGTGCCCGCAAGGGCGGGCGCGCGCGGGCGAGCAGCGTGACGCAG & 199 \\
\hline Assemblage A & 200 & CGACGGCGCGCCCGGGCTTCCGGCGCATCACCCGGGTCGGCGCCGTCGCGG & 249 \\
\hline Livestock & 200 & CGACGGCGCGCCCGGGCTTCCGGCGCATCACCCGGGTCGGCGCCGTCGCGG & 249 \\
\hline Assemblage A & 250 & CGCGCGGAGGGCGCGACGCCTGGCCGAGAATCAGGGTTCGACT & 292 \\
\hline Livestock & 250 & CGCGCGGAGGGCGCGACGCCTGGCCGAGAATCAGGGTTCGACT & 292 \\
\hline
\end{tabular}

Figure 1. Genetic sequences of 16-rRNA gene of Giardia isolates obtained from infected beef buffaloes' calves in Egypt. 


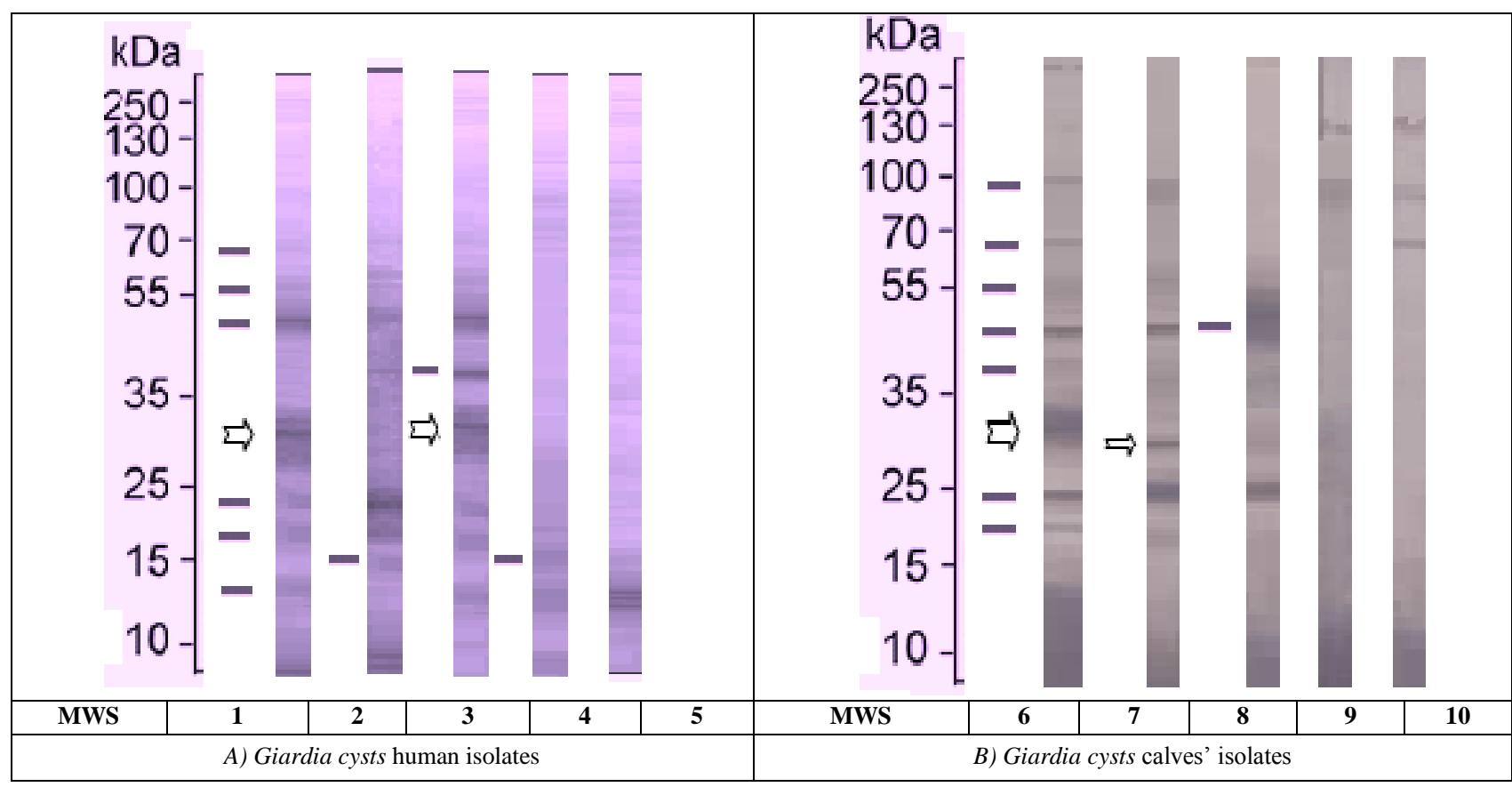

Figure 2. Reaction of different Giardia isolates fraction versus infected human and animal sera. Group (A): NC strip contain fractionated Human isolates (assemblage A) reacted versus; Lane (1): infected child sera (reaction at specific giardin fraction arrow); Lane (2): infected calve sera (No reaction at. giardin fraction); Lane (3): infected calve sera (from out the farm) (reaction at giardin fraction arrow); Lane (4): negative non-infected child sera; Lane (5): negative non-infected calve sera. Group (B): NC strip contain fractionated Calve isolates (assemblage E) reacted versus; Lane (6): Infected calve sera. Present in the closed farm. (Reaction at giardin fraction, arrow); Lane (7): Infected out farm calve sera (narrow reaction at giardin fraction, arrow); Lane (8): Infected human sera (no reaction at bovine giardin fraction); Lane (9): Non-infected calve sera; Lane (10): Non-infected human sera.

Table 1. Prevalence of Giardia cysts in feces of children and their calves in and out of the closed farm in Abo-Rawash village, Giza Governorate, Egypt

\begin{tabular}{|c|c|c|c|c|c|c|c|c|c|}
\hline \multirow{2}{*}{\multicolumn{2}{|c|}{ Inspected localities }} & \multicolumn{4}{|c|}{ Examined diarrheic calves } & \multicolumn{4}{|c|}{ Examined diarrheic children } \\
\hline & & Age groups & No. exam & +Ve No. & $\%$ & Age groups & No. exam. & +Ve No. & $\%$ \\
\hline \multirow{3}{*}{ Closed farm } & & $<2$ months & 15 & 15 & $100 \%$ & $<2$ year & 6 & 4 & 66.66 \\
\hline & & $2-6$ months & 25 & 10 & $40 \%$ & $2-5$ year & 14 & 11 & 78.57 \\
\hline & & Total & 40 & 25 & $62.5 \%$ & Total & 20 & 15 & $75 \%$ \\
\hline \multirow{8}{*}{$\begin{array}{l}\text { Cases examined } \\
\text { outside the } \\
\text { closed farm }\end{array}$} & \multirow{2}{*}{1} & $<2$ months & 6 & 3 & $50 \%$ & $<2$ year & 4 & 2 & $50 \%$ \\
\hline & & $2-6$ months & 11 & 5 & 45.45 & $2-5$ year & 6 & 4 & 66.66 \\
\hline & \multirow{2}{*}{2} & $<2$ months & 8 & 4 & $50 \%$ & $<2$ year & 5 & 2 & $40 \%$ \\
\hline & & $2-6$ months & 12 & 5 & 41.66 & $2-5$ year & 5 & 4 & $80 \%$ \\
\hline & \multirow{2}{*}{3} & $<2$ months & 5 & 3 & $60 \%$ & $<2$ year & 3 & 2 & 66.66 \\
\hline & & 2-6 months & 10 & 4 & $40 \%$ & $2-5$ year & 7 & 5 & 71.43 \\
\hline & \multirow{2}{*}{4} & $<2$ months & 11 & 6 & 54.54 & $<2$ year & 4 & 2 & $50 \%$ \\
\hline & & 2-6 months & 15 & 8 & 53.33 & $2-5$ year & 6 & 3 & $50 \%$ \\
\hline \multirow{3}{*}{ Total } & & $<2$ months & 30 & 16 & 53.33 & $<2$ year & 16 & 8 & $50 \%$ \\
\hline & & $2-6$ months & 48 & 22 & 45.83 & $2-5$ year & 24 & 16 & 66.66 \\
\hline & & Total & 78 & 38 & 48.71 & - & 40 & 24 & $60.0 \%$ \\
\hline
\end{tabular}

*No. exam=Number examined, (+Ve No.) = Postive Number

Table 2. Specific polypeptides bands in fractionated isolates of Giardia cysts from infected children and calves reacted versus different Giardia infected sera.

\begin{tabular}{|c|c|c|c|c|c|c|}
\hline \multirow{4}{*}{$\begin{array}{l}\text { Number of the band } \\
\text { in the plate }\end{array}$} & \multicolumn{6}{|c|}{ Specific polypeptides in fractionated Giardia cysts isolates (KDa) } \\
\hline & \multicolumn{3}{|c|}{ Human assemblage A versus } & \multicolumn{3}{|c|}{ Livestock assemblage $\mathbf{E}$ versus } \\
\hline & \multicolumn{2}{|c|}{ Assembling A infected } & \multirow{2}{*}{$\begin{array}{c}\text { Assemblage E infected } \\
\text { Calves }\end{array}$} & \multirow{2}{*}{$\begin{array}{l}\text { Assemblage } E \text { infected } \\
\text { Calves }\end{array}$} & \multicolumn{2}{|c|}{ Assembling A infected } \\
\hline & Children & Calves & & & Calves & Children \\
\hline 3 & 55 & 55 & 55 & 55 & 55 & 55 \\
\hline 4 & 46 & 46 & 46 & 46 & 46 & $45-50$ \\
\hline 5 & & 38 & 38 & 38 & 38 & 38 \\
\hline 6 & $>29-34$ & $\triangleright 29-34$ & -- & -29-34 & $\triangleright 29$ & -- \\
\hline 7 & 25 & 25 & 25 & 25 & 25 & 25 \\
\hline 8 & & & & 18 & 18 & 18 \\
\hline
\end{tabular}

* Other fractions at MW of 100, 70,15 \& $12 \mathrm{KDa}$ in fractionated children isolates and those at MW of $100 \mathrm{KDa} \& 70 \mathrm{KDa}$ in fractionated calves' isolates were reacted also as non-specific fractions as they react versus infected and non-infected serum samples of children and calves (Plate 1) 
Giardia infection is still considered as a re-emerging zoonotic disease in the rural community in developing countries due to contamination of public water with raw sewage from animal and human sources, lack of water treatment, and use of manure fertilizer in agriculture (Squire and Ryan, 2017). The increase of contact between humans and animals in the rural community, as the case in the present study, could correspond to the higher prevalence of infection by zoonotic Giardia assemblages from humans to animals or vice versa. The recorded percentage of infection in the investigated closed farm where the owners and their children were in continuous daily contact with buffaloes and their calves in the small localized area was higher than that obtained results of a study reported by Ismail et al. (2018) as 10-34.6\% infection among children living in Egypt. This percentage of infection in the investigated localities could be attributed to the nature of the study as it focused on a small community and all of them were symptomatically suffering from diarrhea. The higher level of infection in younger than older groups in the current study was in line with the findings of a study performed by Júlio et al. (2012). However, this finding yield had no support to findings of Samie et al. (2020) that indicated no significant correlation between age and gender concerning the distribution of Giardia infection. The higher rate of infection in children of 2-5 years old compared to those of young age may be attributed to the active movement and increasing rate of contact of children in this age group with animals inside the farm than the really young children.

As genotyping facilitates the identification of various strains of Giardia, the possible public health significance of calves' giardiasis was determined by characterization at a molecular level and genotyping to representative samples from Giardia cysts isolates collected from infected children and calves in the investigated localities. The choice of assay depended on the amount of information carried by the genetic locus under the analysis. The locus of 16SrRNA conceded as one of the highly conserved gene regions that could be used in the detection of Giardia (Almeida et al., 2015). A number of 28 isolates from infected calves and 20 from infected children representing about $50 \%$ of the total isolates were selected and genotyped using nested PCR. Amplification and sequencing of a 292 bp fragment of the 16s-rRNA ribosomal unit revealed infection of children in closed or open farms as well as calves in the closed farm by Giardia assemblage A genotype. The findings addressing these isolates were supported in other related studies as assemblage A1 while calves infected in the open farm harbors "Hoofed livestock" genotype (E). These data indicated predominantly distribution for assemblage A over the Hoofed livestock" genotype (E) in closed farms. In contrast, Gillhuber et al. (2013) mentioned that livestock-specific assemblage E of $G$. duodenalis appeared to be the most frequent genotype in calves.

Infection of calves and children in the closed farm by the same genotype (human assemblage A) and simultaneous infection of calves in the open farms by the Hoofed livestock" genotype (E) demonstrated that the workers inside this closed farm considered to be the source of infection to calves in this closed farm. This was supported by the appearance of infection in all suckling calves born inside this farm and did not move outside. In the same villages, the animals in open farms live in semi-free conditions as they freely moved daily from their pins to field during the day and returned to their pins at the end of the day. Those people with less contact level to such animals were infected by hoofed strain Assemblage $\mathrm{E}$ while their counterparts with semi-contact were infected by the zoonotic assemblage A. This finding agreed with the results of a study carried out by Ramírez et al. (2015) as in some localities, the high prevalence in humans was associated with high prevalence in some of the surrounding animals. Giardiasis is a self-limited disease and its chronic form usually causes severe digestive disturbances; however, the disease may be asymptomatic in some other cases (Liu, 2019). Infected children in the present study were suffering mainly from diarrhea without other complaints. This mild symptom in association with the diagnosed Giardia assemblage isolated from these children was in line with the reports provided by Puebla et al. (2017). They mentioned that there was a relation between the Giardia assemblage and the recorded clinical signs diagnosed in infected individuals. Symptoms of the infection in children harboring assemblage B were more prominent than those in children infected with assemblage A. Moreover, assemblage AI appeared as the most frequent sub-assemblage which was highly associated with animals than humans (Puebla et al., 2017; Sánchez et al., 2017).

Infection of calves by genotype assemblage A isolates has a significant public health risk as generally Giardia cysts are stable, it can survive for weeks or months in the environment. Moreover, even a single cyst can induce infection and the infected individual can shed up to 900 million cysts per day in feces then end up in the environment and can spread to human or animal foods by irrigation or by direct contact (Ryan and Cacciò, 2013). In this regard, the current study demonstrated that animal as a reservoir can be easily infected and then spread the infection after propagation to their surrounding humans, especially in case they were infected by a zoonotic assemblage of the parasite

Another objective of the current study was to investigate the antigenic composition of each assemblage concerning the presence of specific immunogenic fractions related to each assemblage that may be responsible to the development of specific anti-assemblage $\mathrm{Ab}$ in sera of infected human or animals using EITB. The specific fractions in human assemblage A versus infected sera ranged 25-55 KDa. Similarly, the fractions in livestock assemblage E of calves were within the range of $18-55 \mathrm{KDa}$, and most of these fractions were identified as specific by several authors, such as 
Franzen et al. (2009), Sabry et al. (2009), and Feliziani et al. (2011) using EITB. The fraction of 38 KDa appeared to be more related to calves A.G.Abs and calves Giardia Ag. This fraction indicated special relation to the assemblage, but it may be identified as host-related rather than parasite-related. This was in line with a study performed by Ramírez et al. (2015) as the factors determining host specificity of different Giardia assemblage entailed both the host and the parasite.

It was important to demonstrate that the protein fractions corresponding to MW of 29-34 KDa in the fractionated Giardia assemblage A reacted specifically versus sera of children and calves of the closed farm. Since this group of calves were infected by assemblage $\mathrm{A}$ and at the same time, this group of fractions in this assemblage did not react versus sera of calves infected by calves' assemblage E. On the other hand, the fraction group of the same MW (29-34 $\mathrm{KDa}$ ) in fractionated hoofed strain assemblage $\mathrm{E}$ of calve isolates was reacted specifically versus sera of calves infected by this assemblage and did not react versus children or calves' sera infected by Giardia assemblage A. The recorded specificity of this protein group toward the produced specific A.G.Abs in infected sera revealed that it had a specific immunogenic nature significantly related to its original genotype assemblage. This specific group of bands was previously identified by Quintero et al. (2013) as $\alpha-1$ giardin and demonstrated that these fractions were considered to be specific for the diagnosis of A.G.Abs in sera of infected cases. As mentioned by the researchers and supported in the present study, the immunogenic giardins could be considered as a specific group of protein fractions associated with special assemblage and responsible for the production of specifically related Abs in its host species did not cross-react with Abs produced by giardins of other assemblages. These giardins were a parasite, not host related as it reacts versus their Abs in children or calves, which was confirmed by Ramírez et al. (2015).

The presence of a narrow band at MW of $29 \mathrm{KDa}$ in the tested serum sample (Lane 7 in the plate) of one calve from the closed pin may be related to the infection of this calves by zoonotic and non-zoonotic Giardia assemblage. From this view, the diagnosis of this group of fractions using EITB can be used for the preliminary determination of Giardia assemblage before the application of genotyping. This could facilitate the identification of the isolates and help to reduce the number of samples which can be amplified using PCR. In agreement with Sánchez et al., (2017) the determination of the type of the assemblage's anti-parasite antibodies in the infected hosts helps to understand the molecular epidemiology of Giardia. This will contribute to the determination of the disease features, including the clinical association, resistance to treatment, transmission dynamics of the assemblages, and elucidate the zoonotic potential of the disease.

\section{CONCLUSION}

In conclusion, buffalo calves had a high adverse effect on the public health significance of zoonotic Giardia infection in the rural community in Egypt. Immunoblot analyses identified the protein fraction of MW 29-34 KDa as an assemblage specific immunogenic determinant that can be used for assemblage identification using EITB alone or as a preliminary investigation before genotyping assay of the different Giardia isolates. This approach obtained an easy method to identify Giardia genotype by using EITB as a preliminary investigation before genotyping assay.

\section{DECLARATION}

\section{Competing interests}

The authors declare that they have no competing interests.

\section{Author's contribution}

Mohamed M. El-Bahy was the leader of the research team, designed the study, supervised the work, contributed in revising the Manuscript. Reem, M. Ramadan; Marwa, M. Khalifa and Nancy, O. Kamel carried out sample collection and examination, cyst purification, antigen extraction, fractionation of Giardia cyst antigen, determination of specific protein fractions and DNA extraction. Azza, M. Abdel-Wahab carried out the PCR work and sequencing. All authors checked and approved the final version of the manuscript.

\section{REFERENCES}

Almeida JC, Martins FDC, Ferreira Neto JM, Santos MMD, Garcia JL, Navarro IT, Kuroda EK and Freire RL (2015). Occurrence of Cryptosporidium spp. and Giardia spp. in a public water-treatment system, Paraná, Southern Brazil. Revista Brasileira de Parasitologia Veterinária, 24: 303-308. DOI: https://www.doi.org/10.1590/S1984-29612015051

Cacciò SM, Lalle M and Svärd SG (2018). Host specificity in the Giardia duodenalis species complex. Infection, Genetics and Evolution, 66: 335345. DOI: https://www.doi.org/10.1016/j.meegid.2017.12.001

Campbell JD and Faubert GM (1994). Recognition of Giardia lamblia cyst-specific antigens by monoclonal antibodies. Parasite Immunology, 16: 211-219. DOI: https://doi.org/10.1111/j.1365-3024.1994.tb00342.x

Coffey CM, Collier SA, Gleason ME, Yoder JS, Kirk MD, Richardson AM, Fullerton KE and Benedict KM (2020). Evolving Epidemiology of Reported Giardiasis Cases in the United States, 1995-2016. Clinical Infectious Diseases, ciaa128. DOI: https://doi.org/10.1093/cid/ciaa128 
David EB, Coradi ST, Oliveira-Sequeira TCG, Ribolla PEM, Katagiri S and Guimarães S (2011). Diagnosis of Giardia infections by PCR-based methods in children of an endemic area. Journal of Venomous Animals and Toxins including Tropical Diseases, 17: 209-215. DOI: http://doi.org/10.1590/S1678-91992011000200012

Ehsan AM, Geurden T, Casaert S, Parvin SM, Islam TM, Ahmed UM, Levecke B, Vercruysse J and Claerebout E (2015). Assessment of zoonotic transmission of Giardia and Cryptosporidium between cattle and humans in rural villages in Bangladesh. PloS one, 10: 1-11. DOI: http://doi.org/10.1371/journal.pone.0118239

Erlandsen SL, Bemrick WJ, Schupp DE, Shields JM, Jarroll EL, Sauch JF and Pawley JB (1990). High-resolution immunogold localization of Giardia cyst wall antigens using field emission SEM with secondary and backscatter electron imaging. Journal of Histochemistry \& Cytochemistry, 38 : 625-632. DOI: http://doi.org/10.1177/38.5.2332623

Feliziani C, Merino MC, Rivero MR, Hellman U, Pistoresi-Palencia MC and Rópolo AS (2011). Immunodominant proteins $\alpha$-1 giardin and $\beta$-giardin are expressed in both assemblages A and B of Giardia lamblia. BMC Microbiology, 233: 1-10. DOI: http://www.doi.org/10.1186/1471-2180$\underline{11-233}$

Franzen O, Jerlström-Hultqvist J, Castro E, Sherwood E, Ankarklev J, Reiner DS, Palm D, Andersson JO, Andersson B and Svärd SG (2009). Draft genome sequencing of Giardia intestinalis assemblage B isolate GS: is human giardiasis caused by two different species?. PLoS pathogens, 5: 1-14. DOI: http://www.doi.org/10.1371/journal.ppat.1000560

Fugassa MH (2014). Paleoparasitological diagnosis. Part II - Parasite Remains Preserved in Various Materials and Techniques in Microscopy and Molecular Diagnosis. Foundations of Paleoparasitology. International Federation for Tropical Medicine, 223-254. DOI: http://www.doi.org/10.7476/9788575415986.0017

Gillhuber J, Pallant L, Ash A, Thompson RA, Pfister K and Scheuerle MC (2013). Molecular identification of zoonotic and livestock-specific Giardia-species in faecal samples of calves in Southern Germany. Parasites \& Vectors, 6: 1-6. DOI: http://www.doi.org/10.1186/1756-3305-6$\underline{346}$

Hawash Y (2014). DNA extraction from protozoan oocysts/cysts in feces for diagnostic PCR. The Korean Journal of Parasitology, 52: 263-271. DOI: http://www.doi.org/10.3347/kjp.2014.52.3.263

Hooshyar H, Rostamkhani P, Arbabi M and Delavari M (2019). Giardia lamblia infection: review of current diagnostic strategies. Gastroenterology and Hepatology from Bed to Bench, 12: 3-12. DOI: https://pubmed.ncbi.nlm.nih.gov/30949313/

Ismail MA, Eassa AH, Mahgoub AM and El-Dib N (2018). Review of parasitic zoonotic infections in Egypt. Kasr Al Ainy Medical Journal, 24: 91100. DOI: http://www.doi.org/10.4103/kamj.kamj_36_18

Júlio C, Vilares A, Oleastro M, Ferreira I, Gomes S, Monteiro L, Nunes B, Tenreiro R and Ângelo H (2012). Prevalence and risk factors for Giardia duodenalis infection among children: a case study in Portugal. Parasites \& Vectors, 5: 1-8. DOI: http://www.doi.org/10.1186/1756-3305-5-22

Laemmli UK (1970). Cleavage of structural proteins during the assembly of the head of Bacteriophage T 4. Nature, 227: 680- 685. DOI: http://www.doi.org/10.1038/227680a0

Liu J (2019). Characterization of secreted Giardia intestinalis cysteine proteases (Doctoral dissertation, Acta Universitatis Upsaliensis). DOI: https://www.uu.diva-portal.org/smash/get/diva2:1277339/FULLTEXT01.pdf

Mahmoudi MR, Mahdavi F, Ashrafi K, Forghanparast K, Rahmati B, Mirzaei A, Roshan ZA and Karanis P (2020). Report of Giardia assemblages and giardiasis in residents of Guilan province-Iran. Parasitology Research, 119: 1083-1091. DOI: http://www.doi.org/10.1007/s00436-019$\underline{06595-1}$

Puebla LJ, Núñez FA, García AB, Rivero LR, Millán IA and Prado RC (2017). Prevalence of Giardia duodenalis among children from a central region of Cuba: molecular characterization and associated risk factors. Journal of Parasitic Diseases, 41: 405-413. DOI: http://www.doi.org/10.1007/s12639-016-0816-Z

Quintero J, Figueroa DC, Barcelo R, Breci L, Astiazaran-Garcia H, Rascon L, Robles-Zepeda R, Garibay-Escobar A, Velazquez-Contreras E, Avila GL, Hernandez-Hernandez JM et al. (2013). Identification of an immunogenic protein of Giardia lamblia using monoclonal antibodies generated from infected mice. Memórias do Instituto Oswaldo Cruz, 108: 616-622. DOI: http://www.doi.org/10.1590/0074$\underline{0276108052013013}$

Ramírez JD, Ramos RD, Hernández DC and Leon CM (2015). Molecular diagnosis and genotype analysis of Giardia duodenalis in asymptomatic children from a rural area in central Colombia. Infection, Genetics and Evolution, 32: 208-213. DOI: http://www.doi.org/10.1016/j.meegid.2015.03.015

Ryan U and Cacciò SM (2013). Zoonotic potential of Giardia. International Journal for Parasitology, 43: 943-956. DOI: http://www.doi.org/10.1016/j.ijpara.2013.06.001

Sabry MA, Taher ES and Meabed EMH (2009). Prevalence and genotyping of zoonotic Giardia from Fayoum Governorate, Egypt. Research Journal of Parasitology, 4: 105-114. DOI: http://www.doi.org/10.3923/jp.2009.105.114

Saiki RK, Gelfand DH, Stoffel S, Scharf SJ, Higuchi R, Horn GT, Mullis KB and Erlich HA (1988). Primer-directed enzymatic amplification of DNA with thermostable DNA polymerase. Science, 239: 487-491. DOI: http://www.doi.org/10.1126/science.239.4839.487

Samie A, Tanih NF, Seisa I, Seheri M, Mphahlele J, ElBakri A and Mbati P (2020). Prevalence and genetic characterization of Giardia lamblia in relation to diarrhea in Limpopo and Gauteng provinces, South Africa. Parasite Epidemiology and Control, 9: 1-8. DOI: http://www.doi.org/10.1016/j.parepi.2020.e00140

Sánchez A, Munoz M, Gómez N, Tabares J, Segura L, Salazar Á, Restrepo C, Ruíz M, Reyes P, Qian Y, Xiao L et al. (2017). Molecular epidemiology of Giardia, Blastocystis and Cryptosporidium among indigenous children from the Colombian Amazon Basin. Frontiers in Microbiology, 8: 1-14. DOI: http://www.doi.org/10.3389/fmicb.2017.00248

Squire SA and Ryan U (2017). Cryptosporidium and Giardia in Africa: current and future challenges. Parasites \& Vectors, 10: 1-32. DOI: http://www.doi.org/10.1186/s13071-017-2111-y

Thompson JD, Higgins DG and Gibson TJ (1994). CLUSTAL W: Improving the sensitivity of progressive multiple sequence alignment through sequence weighting, position-specific gap penalties and weight matrix choice. Nucleic Acids Research, 22: 4673-4680. DOI: http://www.doi.org/10.1093/nar/22.22.4673

Towbin H, Stachelin T and Gordon J (1979). Electrophoretic transfer of proteins from polyacrylamide gels to nitrocellulose sheets. Procedures and some applications. Proceedings of the National Academy of Sciences, USA, 76: 4350- 4354. DOI: http://www.doi.org/10.1073/pnas.76.9.4350

Trout JM, Santin M, Greiner E and Faye R (2004). Prevelance of G.duodenalis genotypes in pre-weand dairy calves. Vet Parasitology, 124: $179-186$. DOI: https://www.doi.org/10.1016/j.vetpar.2004.07.010 